\title{
REGULATION OF $\alpha$-BUNGAROTOXIN RECEPTOR ACCUMULATION IN CHICK RETINA CULTURES: EFFECTS OF MEMBRANE DEPOLARIZATION, CYCLIC NUCLEOTIDE DERIVATIVES, AND Ca ${ }^{2+}$
}

\author{
HEINRICH BETZ ${ }^{1}$
}

Max Planck Institute for Psychiatry, Department of Neurochemistry, 8033 Martinsried, Federal Republic of Germany

Received October 6, 1982; Revised January 3, 1983; Accepted January 18, 1983

\begin{abstract}
The regulation of a putative neuronal nicotinic acetylcholine receptor, the $\alpha$-bungarotoxin ( $\alpha$ Btx)-binding protein, was investigated in primary cultures of chick embryo retina. Depolarization of the cells by veratrum alkaloids, or by a high $\mathrm{K}^{+}$concentration of the culture medium, reduced the accumulation of cell surface $\alpha$-Btx receptors in these cultures. In contrast, the addition of a blocker of voltage-dependent $\mathrm{Na}^{+}$channels, tetrodotoxin, increased $\alpha$-Btx receptor accumulation in differentiated retina cultures. Derivatives of cyclic adenosine $3^{\prime}: 5^{\prime}$-monophosphate also increased the number of $\alpha$-Btx receptor sites, whereas dibutyryl cyclic guanosine $3^{\prime}: 5^{\prime}$-monophosphate, but not 8bromo-cyclic guanosine $3^{\prime}: 5^{\prime}$-monophosphate, had the opposite effect. The blocker of voltagedependent $\mathrm{Ca}^{2+}$ channels, D600, and media containing a reduced $\mathrm{Ca}^{2+}$ concentration also increased $\alpha$-Btx receptor levels. All of these different culture conditions altered the rate of $\alpha$-Btx receptor incorporation into the cell membrane, but did not significantly affect the rate of receptor loss after blocking protein synthesis by cycloheximide. These results show that the synthesis of the neuronal $\alpha$-Btx receptor is regulated by membrane depolarization, cyclic nucleotides, and $\mathrm{Ca}^{2+}$ in a fashion analogous to the regulation of muscle acetylcholine receptor.
\end{abstract}

A central question in neurobiology concerns the molecular mechanisms by which the number and the cell surface distribution of synaptic proteins are regulated. Studies on the developing neuromuscular junction have shown that neurally induced muscle activity plays an important role in the control of nicotinic acetylcholine receptor synthesis and in the synaptic localization of acetylcholinesterase (Drachman and Witzke, 1972; Lømo and Rosenthal, 1972; Giacobini et al., 1973; Burden, 1977; Hall and Reiness, 1977; Bourgeois et al., 1978; Fambrough, 1979; Betz et al., 1980; Rubin et al., 1980; Lømo and Slater, 1980). The intracellular events which couple muscle activity to the regulation of these postsynaptic proteins are not yet identified. However, some of the effects that are produced by muscle activity can be mimicked in tissue culture (Betz and Changeux, 1979; Rubin et al., 1980) by membrane-depolarizing drugs, such as veratrum alkaloids, or by dibutyryl cyclic guanosine $3^{\prime}: 5^{\prime}$-monophosphate (cGMP). Also, an antagonist of

\footnotetext{
' This work was supported by the Deutsche Forschungsgemeinschaft (Grant Be 718/5,6 and Heisenberg Fellowship Be 718/4). I wish to thank Ms. U. Müller for expert technical assistance, Drs. D. Graham and F. Pfeiffer for a critical reading of the manuscript, Mrs. H. Macher, U. Grenzemann, and C. Bauereiss for help during its preparation, and the Max-Planck-Gesellschaft for the provision of laboratory facilities.
}

voltage-dependent $\mathrm{Ca}^{2+}$ channels, $\mathrm{D} 600$, has been shown to increase acetylcholine receptor synthesis in cultured myotubes (Prives, 1976). Therefore, it was postulated that changes in $\mathrm{Ca}^{2+}$ influx and cyclic nucleotide levels during electrical activity may act as second messengers in the regulation of the acetylcholine receptor and of the synaptic form of acetylcholinesterase (Betz and Changeux, 1979; Betz and Rehm, 1980a; Birnbaum et al., 1980).

In this paper, the possibility that similar regulatory mechanisms may also apply for CNS postsynaptic proteins was investigated. For this purpose, the expression of a neuronal membrane protein identified by binding of the nicotinic cholinergic antagonist, $\alpha$-bungarotoxin $(\alpha$ Btx), was studied in primary cultures of chick retina. Different groups have shown that $\alpha$-Btx binding to avian retina is associated with a glycoprotein that shares biochemical, pharmacological, and immunological similaritics with the acetylcholine receptor from muscle and fish electric organ (Vogel and Nirenberg, 1976; Wang et al., 1978; Betz, 1981a; Betz et al., 1982; Norman et al., 1982). Also, during development the $\alpha$-Btx-binding site becomes localized at synapses (Vogel et al., 1977; Daniels and Vogel, 1981). However, as the association of neuronal $\alpha$ Btx-binding sites with nicotinic acetylcholine receptors is still a matter of debate (for discussion see Betz, 1981a; Morley and Kemp, 1981; Oswald and Freeman, 1981), I 
will refer to this protein here as " $\alpha$-Btx receptor." The present report shows that the synthesis of the $\alpha$-Btx receptor in retina cultures can be modulated by membrane depolarization, by cyclic nucleotide derivatives, and by $\mathrm{Ca}^{2+}$ and its antagonists. Some of these results have been presented in preliminary form (Betz and Rehm, 1980b).

\section{Materials and Methods}

Materials. Dulbecco's modified Eagle's medium (DMEM), fetal calf serum, horse serum, penicillin, and streptomycin were purchased from Gibco Biocult, Karlsruhe, Germany. Insulin, transferrin, putrescine, progesterone, isobutyl methylxanthine, and veratrine were from Sigma Chemical Co., St. Louis, MO. Tetrodotoxin, 8bromo-cyclic adenosine $3^{\prime}: 5^{\prime}$-monophosphate (cAMP), dibutyryl-cGMP, and bovine serum albumin were obtained from Boehringer, Mannheim, Germany, and cycloheximide and $d$-tubocurarine were from Serva, Heidelberg, Germany. $\alpha$-Btx was purchased from Miami Serpentarium Laboratories, Miami, FL. ${ }^{125}$ I-labeled $\alpha$ Btx $\left(\left[{ }^{125} \mathrm{I}\right] \alpha\right.$-Btx, initial specific activity 100 to $150 \mathrm{Ci} /$ $\mathrm{mmol}), \mathrm{Na}^{125} \mathrm{I}(17 \mathrm{Ci} / \mathrm{mg})$, and $\left[{ }^{3} \mathrm{H}\right]$ triphenylmethyl phosphonium $\left(\left[{ }^{3} \mathrm{H}\right] \mathrm{TPMP}^{+}\right)$bromide $(3.59 \mathrm{Ci} / \mathrm{mmol})$ were from New England Nuclear, Dreieich, Germany. For some experiments, $\alpha$-Btx was labeled to higher specific activities $(500 \mathrm{Ci} / \mathrm{mmol})$ using the chloramine $\mathrm{T}$ method as described previously (Betz et al., 1980). L-[4,5- $\left.{ }^{3} \mathrm{H}\right]$ leucine $(52 \mathrm{Ci} / \mathrm{mmol})$ was from Amersham-Buchler, Braunschweig, Germany, and Unisolve 100 scintillation cocktail was from Koch Light-Zinsser, Frankfurt, Germany. D600 was a gift from Knoll Chemie, Ludwigshafen, Germany. Monensin and the $\mathrm{Ca}^{2+}$ ionophore A 23187 were gifts from Eli Lilly and Co., Indianapolis, IN; felodipine and nifedipine were gifts of AB Hässle, Mölndal, Sweden. Dendroaspis viridis toxin 4.9.3 ( $\alpha$-mambatoxin) was isolated from the venom of $D$. viridis according to published procedures (Shipolini et al., 1973; Patrick et al., 1980); the venom was a gift of Dr. C. Bon, Institut Pasteur, Paris. All other chemicals were of reagent grade.

Culture conditions. Monolayer cultures from retinas of 8-day-old chick embryos were prepared as described previously (Betz, 1981a). If not otherwise stated, DMFM containing $5 \%(\mathrm{v} / \mathrm{v})$ fetal calf serum, $5 \%(\mathrm{v} / \mathrm{v})$ horse serum, $100 \mathrm{units} / \mathrm{ml}$ of penicillin, and $100 \mu \mathrm{g} / \mathrm{ml}$ of streptomycin ("complete medium," COM) was used as culture medium. In some experiments, the cultures were maintained for up to 5 days in DMEM-based, serum-free, hormone-supplemented N1 medium (Bottenstein et al., 1980; Retz and Müller, 1982). $\mathrm{Ca}^{2+}$-free $\mathrm{N} 1$ medium was prepared by adding the supplements to DMEM without $\mathrm{CaCl}_{2}$. Media containing different concentrations of $\mathrm{K}^{+}$ were made by mixing normal DMEM with DMEM in which $\mathrm{Na}^{+}$was isotonically replaced by $\mathrm{K}^{+}$. Additions to the culture media were made from 100-fold concentrated stock solutions of the drugs in phosphate-buffered saline or DMEM. Where necessary, the $\mathrm{pH}$ of the stock solutions was adjusted to 7.4 with $1 \mathrm{~N} \mathrm{NaOH}$. D600, monensin, and A 23187 were added from stock solutions in ethanol; in these experiments, all media contained ethanol at a final concentration of $0.1 \%(\mathrm{v} / \mathrm{v})$. The media and the additives were changed every second day. $\left[{ }^{125} I\right] \alpha-B t x$ binding. $\left[{ }^{125} \mathrm{I}\right] \alpha-\mathrm{Btx}$ binding to intact cultures was always determined in COM as described previously (Betz, 1981a). Most experiments were performed two to five times with different sets of cultures. Because the amount of $\left[{ }^{125} \mathrm{I}\right] \alpha-\mathrm{Btx}$ binding to control cultures varied between different experiments, the data from individual experiments have been expressed as a percentage of $\left[{ }^{125} \mathrm{I}\right] \alpha$-Btx binding to control cultures, and then the values from different experiments were combined. The time course of $\alpha$-Btx receptor and protein accumulation under our culture conditions has been published (Betz, 1981a). Typically, 6-day-old cultures contained 40 to $70 \mathrm{fmol}$ of $\left[{ }^{125} \mathrm{I}\right] \alpha$-Btx-binding sites/dish, and 0.4 to 0.8 $\mathrm{mg}$ of protein/dish.

Protein determination. Protein was determined by the method of Lowry et al. (1951) using bovine serum albumin as a standard.

Protein synthesis. Protein synthesis was measured by the incorporation of $\mathbf{L}-\left[4,5-{ }^{3} \mathrm{H}\right]$ leucine into trichloroacetic acid-precipitable material using a glass fiber filtration assay (Betz and Weiser, 1976; Betz and Changeux, 1979).

Protein degradation. Retina cultures were grown for 2 days in $\mathrm{COM}$ containing $1 \mu \mathrm{Ci} / \mathrm{ml}$ of $\mathrm{L}-\left[4,5-{ }^{3} \mathrm{H}\right]$ leucine. At the onset of the experiment, five dishes were removed to determine the incorporation of radioactivity into trichloroacetic acid-precipitable material (Betz and Weiser, 1976). The remaining cultures were washed three times and incubated in COM containing $10 \mathrm{~mm}$ leucine as a chase and, if specified, other additives. After 8 to $10 \mathrm{hr}$, the radioactivity released into the culture medium and the trichloroacetic acid-precipitable radioactivity remaining in the cells were determined.

Uptake of $\left.{ }^{3} \mathrm{H}\right] T P M P^{+}$. The steady-state accumulation of the lipophilic cation $\left[{ }^{3} \mathrm{H}\right] \mathrm{TPMP}{ }^{+}$by retinal cells was determined as described by Lichtstein et al. (1979) with the following modifications. Retina cultures were incubated at $37^{\circ} \mathrm{C}$ for $40 \mathrm{~min}$ with different culture media containing $1 \mu \mathrm{Ci} / \mathrm{ml}$ of $\left[{ }^{3} \mathrm{H}\right] \mathrm{TPMP}{ }^{+}$. The medium then was removed, and the cultures were rapidly washed with $3 \mathrm{ml}$ of phosphate-buffered saline. Cellular radioactivity was extracted in $1 \mathrm{~N} \mathrm{NaOH}$ containing $1 \%(\mathrm{w} / \mathrm{v})$ Triton $\mathrm{X}-100$. Aliquots of the extracts were counted in $8 \mathrm{ml}$ of Unisolve 100. The data were corrected for membrane potential-independent $\left[{ }^{3} \mathrm{H}\right] \mathrm{TPMP}^{+}$uptake determined in the presence of $80 \mathrm{mM} \mathrm{K}^{+}$. Control experiments showed that under our conditions, $\left[^{3} \mathrm{H}\right] \mathrm{TPMP}^{+}$uptake was saturated at about $30 \mathrm{~min}$, and that up to three washes of the cells within $25 \mathrm{sec}$ did not cause a significant loss of cellular radioactivity. Also, steady-state $\left[{ }^{3} \mathrm{H}\right] \mathrm{TPMP}^{+}$accumulation by the cultures was a linear function of the $\left[{ }^{3} \mathrm{H}\right] \mathrm{TPMP}^{+}$concentration in the medium.

\section{Results}

Effects of veratrine, tetrodotoxin, and high $\mathrm{K}^{+}$on the number of $\alpha$-Btx receptors of retina cultures. Monolayer cultures of retinal cells dissociated from 8-day-old chick embryos accumulate cell surface receptors for $\left.{ }^{[25} \mathrm{I}\right] \alpha$-Btx during 1 to 2 weeks in vitro (Vogel and Nirenberg, 1976; Betz, 1981a). In Table I, it is shown that retina cultures grown in the presence of veratrine, a mixture of veratrum alkaloids containing the depolarizing drug veratridine, contained significantly fewer cell surface-binding sites for 
TABLE I

Effects of veratrine, tetrodotoxin, and high $K^{+}$on $\left.{ }^{125} I\right] \alpha-B t x$ binding to retina cultures

The cultures were grown in COM and exposed to the various culture conditions listed below from either days 2 to 6 or days 7 to 11 . The concentration of veratrine was $59 \mu \mathrm{g} / \mathrm{ml}$, and that of tetrodotoxin was $10 \mu \mathrm{M}$. After either the 6 th or the 11 th day, $\left[{ }^{195} \mathrm{I}\right] \alpha-\mathrm{Btx}$ binding and protein were determined as described under "Materials and Methods." The data represent the mean \pm SD from $n$ individual experiments with three to five determinations, each. The SD of controls was between 4 and $13 \%$.

\begin{tabular}{|c|c|c|c|}
\hline Culture Condition & $\begin{array}{c}{\left[{ }^{125} I\right] \alpha-\text { Btx Bound } / \text { Dish }} \\
\text { (\% control) }\end{array}$ & $\begin{array}{l}\text { Protein } / \text { Dish } \\
\text { (\% control) }\end{array}$ & $n$ \\
\hline \multicolumn{4}{|l|}{ I. Treatment from days $2-6$} \\
\hline + Veratrine & $61 \pm 6^{a}$ & $92 \pm 5$ & 6 \\
\hline + Tetrodotoxin & $103 \pm 6$ & $96 \pm 5$ & 4 \\
\hline$+56 \mathrm{mM} \mathrm{K}^{+}$ & $73 \pm 4^{\alpha}$ & $110 \pm 10$ & 2 \\
\hline \multicolumn{4}{|l|}{$\begin{array}{l}\text { II. Treatment from days 7- } \\
11\end{array}$} \\
\hline+ Veratrine & $62 \pm 4^{a}$ & $96 \pm 6$ & 2 \\
\hline+ Tetrodotoxin & $165 \pm 23^{a}$ & $109 \pm 8$ & 3 \\
\hline $\begin{array}{l}\text { + Veratrine and tetrodo- } \\
\text { toxin }\end{array}$ & $162 \pm 24^{a}$ & $85 \pm 5$ & 1 \\
\hline$+56 \mathrm{mM} \mathrm{K}^{+}$ & $49 \pm 13^{a}$ & $90 \pm 7$ & 1 \\
\hline
\end{tabular}

${ }^{a}$ Significantly different from control cultures: $p<0.01$.

$\left[{ }^{125} \mathrm{I}\right] \alpha$-Btx than did control cultures. In contrast, a blocker of voltage-dependent sodium channels, tetrodotoxin, increased $\left[{ }^{125} \mathrm{I}\right] \alpha$-Btx binding to the cells; however, this effect was only observed in cultures older than 6 days. Presumably, the latter drug blocked the spontaneous activity of the neurons that had matured in vitro. Also, tetrodotoxin antagonized the effect of veratrine, suggesting that the action of the alkaloids was exerted by the activation of action potential sodium channels. Under all of these conditions, there was no significant change in the protein content of the cultures or in the $K_{\mathrm{D}}\left(0.7 \mathrm{nM}\right.$; Betz, 1981a) of $\left[{ }^{125} \mathrm{I}\right] \alpha$-Btx binding (data not shown). The observed differences in $\left[{ }^{125} \mathrm{I}\right] \alpha$-Btx binding thus were due to changes in the number of $\alpha$-Btx receptors; i.e., receptor accumulation.

A reduction in $\alpha$-Btx receptor number was also produced by depolarizing the cells with medium containing $56 \mathrm{mM} \mathrm{K}^{+}$(Table I). Concentrations of $\mathrm{K}^{+}$up to $20 \mathrm{~mm}$ had no effect (Fig. 1). The half-maximal decrease in $\alpha$ toxin binding occurred at $\mathrm{K}^{+}$concentrations between 20 and $40 \mathrm{~mm}$. This corresponded to a significant depolarization of the cells as revealed by a 30 to $40 \%$ reduction in the uptake of the lipophilic cation $\left[{ }^{3} \mathrm{H}\right] \mathrm{TPMP}^{+}$(Fig. 1). From the difference in $\left[{ }^{3} \mathrm{H}\right] \mathrm{TPMP}^{+}$uptake at 0 and 45 min under fully depolarizing conditions $\left(80 \mathrm{mM} \mathrm{K} \mathrm{K}^{+}\right)$, an internal volume of $3.2 \pm 0.3 \mu \mathrm{l} / \mathrm{ml}$ of protein was calculated for 5-day-old retina cultures. Using this value, the half-maximal reduction in $\left.{ }^{125} \mathrm{I}\right] \alpha$-Btx binding was estimated to occur at a transmembrane potential of about -20 to $-30 \mathrm{mV}$ (Lichtstein et al., 1979).

Effects of cyclic nucleotide derivatives on the number of $\alpha-B t x$ receptors of retina cultures. The addition of cyclic nucleotide derivatives to the culture medium also affected the number of $\left.{ }^{125} \mathrm{I}\right] \alpha$-Btx-binding sites of chick retina cultures. The cAMP derivatives 8 -bromo-cAMP and, to a lesser extent, dibutyryl-cAMP both increased $\alpha$-Btx receptor accumulation at concentrations of 200 to

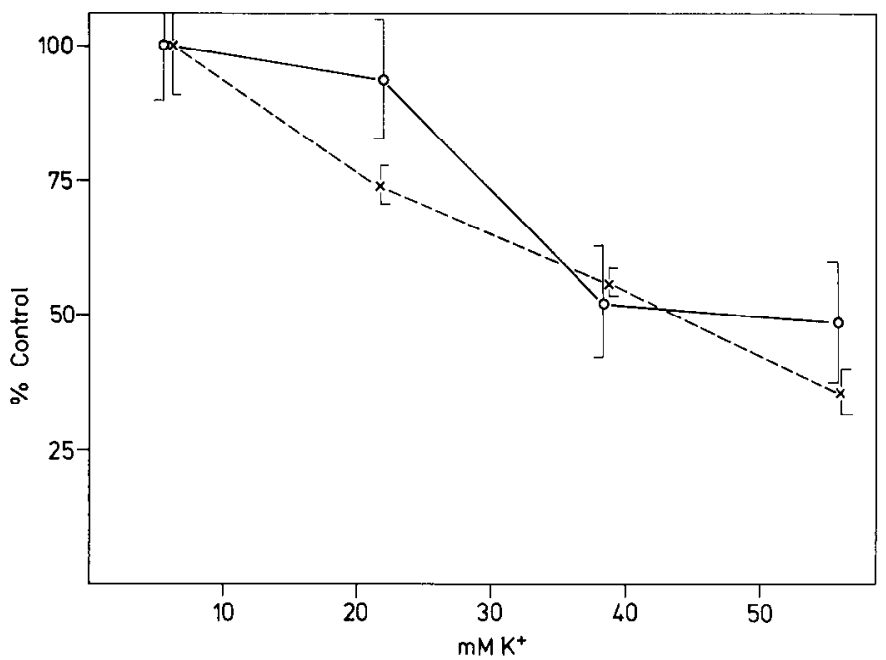

Figure 1. Effect of increasing concentrations of $\mathrm{K}^{+}$in the culture medium on $\left[{ }^{125} \mathrm{I}\right] \alpha$-Btx binding and $\left[{ }^{3} \mathrm{H}\right] \mathrm{TPMP}^{+}$uptake of retina cultures. The cultures were grown in COM for 1 day as detailed under "Materials and Methods." Then the medium was changed to $\mathrm{N} 1$ medium containing the indicated concentrations of $\mathrm{K}^{+}$. After the 5th day, $\left[{ }^{3} \mathrm{H}\right] \mathrm{TPMP}^{+}$uptake in the presence of the indicated concentrations of $\mathrm{K}^{+}$and $\left[{ }^{125} \mathrm{I}\right] \alpha-\mathrm{Btx}$ binding were determined. The data are the mean $\pm \mathrm{SD}$ of different experiments with three to four determinations, each, and are expressed as percentage of control values obtained in N1 medium (28 to 40 frnol of $\left[{ }^{125} \mathrm{I}\right] \alpha-\mathrm{Btx}$ bound/dish; 60 to 100 pmol of $\left[{ }^{3} \mathrm{H}\right] \mathrm{TPMP}{ }^{+}$taken up/dish). $O,\left[{ }^{125} \mathrm{I}\right] \alpha$-Btx bound per dish; $x,\left[{ }^{3} \mathrm{H}\right] \mathrm{TPMP}^{+}$uptake per dish.

\section{TABLE II}

Effects of cyclic nucleotide derivatives and isobutyl methylxanthine on $\left[^{125} I\right] \alpha-B t x$ binding to retina cultures

The cultures were grown in COM and treated with the specified agents from days 2 to 6 . $\left[{ }^{125} \mathrm{I}\right] \alpha$-Btx binding and protein were then determined as described under "Materials and Methods." The data are the mean \pm SD from $n$ individual experiments with three to four determinations, each. The SD of controls was between 5 and $12 \%$.

\begin{tabular}{lccc}
\hline \multicolumn{1}{c}{ Culture Condition } & $\begin{array}{c}\left.{ }^{125} \mathrm{I}\right] \alpha \text {-Btx Bound/Dish } \\
(\% \text { control) }\end{array}$ & $\begin{array}{c}\text { Protein/Dish } \\
\text { (\% control) }\end{array}$ & $n$ \\
\hline +Dibutyryl-cAMP $(500 \mu \mathrm{M})$ & $122 \pm 8^{a}$ & $92 \pm 11$ & 3 \\
+ 8-Bromo-cAMP $(200 \mu \mathrm{M})$ & $162 \pm 24^{a}$ & $110 \pm 11$ & 4 \\
+Dibutyryl-cGMP $(500 \mu \mathrm{M})$ & $65 \pm 17^{a}$ & $88 \pm 12$ & 7 \\
+ 8-Bromo-cGMP $(200 \mu \mathrm{M})$ & $117 \pm 1$ & $105 \pm 6$ & 2 \\
+ Isobutyl methylxanthine & $102 \pm 9$ & $99 \pm 8$ & 2
\end{tabular}
$(100 \mu \mathrm{M})$

${ }^{a}$ Significantly different from control cultures: $p<0.01$.

$500 \mu \mathrm{M}$ (Table II). The cGMP derivative dibutyrylcGMP, in contrast, reduced receptor numbers; however, $200 \mu \mathrm{M}$ 8-bromo-cGMP had no significant effect. The treatment with cyclic nucleotide derivatives had only minor effects on the total protein content of the cultures, indicating that the observed alterations in $\left[{ }^{125} \mathrm{I}\right] \alpha$-Btx binding were relatively selective and were not due to a general modulation of protein metabolism (see also Table IV). At a concentration of $100 \mu \mathrm{M}$, the phosphodiesterase inhibitor isobutyl methylxanthine did not significantly change the number of $\left[{ }^{125} \mathrm{I}\right] \alpha$-Btx-binding sites.

Additional experiments using 8-bromo-cAMP and dibutyryl-cGMP showed $(i)$ that half-maximal effects on $\left[{ }^{125} \mathrm{I}\right] \alpha-\mathrm{B}$ (x binding were observed at about $50 \mu \mathrm{M}$ for 8 
bromo-cAMP and at about $100 \mu \mathrm{M}$ for dibutyryl-cGMP, and (ii) that maximal effects were obtained at 150 and $300 \mu \mathrm{M}$, respectively. Also, the effects of the cyclic nucleotide derivatives were slower than those of high $\mathrm{K}^{+}$or tetrodotoxin, with at least 1 day of incubation being required (data not shown). This was particularly true for dibutyryl-cGMP, where significant changes in toxin binding were detected only after 2 to 3 days of incubation. These effects were only observed in the continuous presence of the cyclic nucleotide derivatives: cultures maintained for periods of $2 \mathrm{hr}$ to 2 days in the presence of 200 $\mu \mathrm{M}$ 8-bromo-cAMP, or $500 \mu \mathrm{M}$ dibutyryl-cGMP, and for another 2 days without drug exhibited $\alpha$-Btx receptor levels not significantly different from those of control cultures (data not shown). Control experiments showed that the effects of the cyclic nucleotide derivatives could not be mimicked by 1 mм ATP, ADP, AMP, GTP, GDP, adenosine, or $S$-adenosylmethionine (data not shown).

The modulation of $\alpha$-Btx receptors by cyclic nucleotide derivatives could not be explained by respective changes in the membrane potential of the cells. Using $\left[{ }^{3} \mathrm{H}\right]$ $\mathrm{TPMP}^{+}$, the uptake of this lipophilic cation was not significantly altered by growing the cultures in the presence of $200 \mu \mathrm{M}$ 8-bromo-cAMP (115 $\pm 10 \%$ of control). Treatment with $500 \mu \mathrm{M}$ dibutyryl-cGMP increased the uptake of $\left.{ }^{3} \mathrm{H}\right] \mathrm{TPMP}^{+}(168 \pm 20 \%$ of control; $n=2 ; p<$ 0.01 ); that is, it produced a hyperpolarization but not a depolarization of the cells.

Effects of $\mathrm{Ca}^{2+}$ antagonists and $\mathrm{Ca}^{2+}$ withdrawal on the number of $\alpha-B t x$ receptors of retina cultures. When retina cultures were maintained in the presence of a blocker of voltage-sensitive $\mathrm{Ca}^{2+}$ channels, D600, the number of $\alpha$-Btx receptors per dish increased by a factor of 1.5 to 2.0 (Table III). A similar, however smaller, effect could also be achieved by adding $20 \mathrm{~mm} \mathrm{MgCl}_{2}$ to the culture medium. Reducing the free $\mathrm{Ca}^{2+}$ concentration of the medium by the addition of EGTA, or using a defined $\mathrm{Ca}^{2+}$-free medium (N1 without $\mathrm{Ca}^{2+}$ ), also increased the number of cell surface receptors for $\alpha$-Btx. Except for EGTA, all of these treatments had no significant effect on the protein content of the cultures.

Several $\mathrm{Ca}^{2+}$ antagonists, which have been reported to act on $\mathrm{Ca}^{2+}$-binding proteins (Boström et al., 1981) rather than on $\mathrm{Ca}^{2+}$ channels, i.e., nifedipine $(1 \mu \mathrm{M})$, felodipine $(1 \mu \mathrm{M})$, and trifluoperazine $(100 \mu \mathrm{M})$, did not significantly alter the accumulation of $\alpha$-Btx receptors in retina cul-

\section{TABLE III}

Effects of $D 600, \mathrm{MgCl}_{2}, \mathrm{EGTA}$, and $\mathrm{Ca}^{2+}$-free medium on $\left[^{125} \mathrm{I} / \alpha-\mathrm{B} t x\right.$ binding to retina cultures

The cultures were grown in COM, or N1 medium, and maintained under the conditions specified below from either days 2 to 6 or days 3 to 7 . The data represent the mean \pm SD from $n$ individual experiments, each with three to four determinations. The SD of controls was between 5 and $16 \%$.

\begin{tabular}{lccc}
\hline \multicolumn{1}{c}{ Culture Condition } & $\begin{array}{c}{\left[^{125} \mathrm{~T}\right] \alpha-\text { Btx Bound/Dish }} \\
\text { (\% control) }\end{array}$ & $\begin{array}{c}\text { Protein/Dish } \\
\text { (\% control) }\end{array}$ & $n$ \\
\hline$+\mathrm{D} 600(10 \mu \mathrm{M})$ & $186 \pm 23^{a}$ & $101 \pm 8$ & 2 \\
$+\mathrm{MgCl}_{2}(20 \mathrm{mM})$ & $143 \pm 14^{a}$ & $89 \pm 6$ & 2 \\
$+\mathrm{EGTA}^{\alpha}(2 \mathrm{mM})$ & $171 \pm 18^{a}$ & $75 \pm 14^{a}$ & 5 \\
$+\mathrm{Ca}^{2+}$-free N1 medium & \\
\hline
\end{tabular}

${ }^{a}$ Significantly different from control cultures: $p<0.01$.

${ }^{b}$ Compared to cultures maintained in N1 medium. tures (data not shown). Nontoxic concentrations of the $\mathrm{Na}^{+}$ionophore, monensin $(10 \mathrm{nM})$, and of the $\mathrm{Ca}^{2+}$ ionophore, A23187 (10 to $100 \mathrm{~nm}$ ), also had no effect. At $1 \mu \mathrm{M}$, A23187 produced a $>50 \%$ reduction in $\alpha$-Btx receptor number. Under these conditions, however, the protein content of the cultures also was drastically reduced.

Additivity of effects of membrane depolarization, cyclic nucleotide derivatives, and $\mathrm{Ca}^{2+}$ withdrawal. In order to evaluate whether the different culture conditions used above produced their effects on $\alpha$-Btx receptor accumulation via a common mechanism, some experiments were performed in which retina cultures were grown in the presence of mixtures of effectors. Under all conditions tested, the effect of 8-bromo-cAMP was additive to that of veratrine, tetrodotoxin, or EGTA (Table IV). This suggests that the action of this cyclic nucleotide derivative is different from that of the other compounds tested. In contrast, the mixture of veratrine and dibutyryl-cGMP produced a reduction in the number of $\left[{ }^{125} \mathrm{I}\right]$ $\alpha$-Btx-binding sites comparable to that found with either compound alone. Membrane depolarization and dibutyryl-cGMP thus may trigger a common intracellular regulation mechanism. Also, dibutyryl-cGMP inhibited the stimulatory effect on $\alpha$-Btx receptor accumulation of both tetrodotoxin and EGTA. Furthermore, $\mathrm{Ca}^{2+}$ withdrawal by EGTA was additive to the decrease in $\left[{ }^{125} \mathrm{I}\right] \alpha-$ Btx-binding sites produced by veratrine, but not to that of tetrodotoxin. Also, the stimulation of $\alpha$-Btx receptor accumulation produced by D600 was not additive to that of tetrodotoxin. These results suggested $(i)$ that most of the extracellular $\mathrm{Ca}^{2+}$ is not essential for the reduction of $\alpha$-Btx receptor accumulation produced by veratrine-induced membrane depolarization or by dibutyryl-cGMP, and (ii) that $\mathrm{Ca}^{2+}$ withdrawal, tetrodotoxin, and $\mathrm{D} 600$ all

\section{TABLE IV}

Additivity of effects of membrane depolarization, cyclic nucleotide derivatives, and $\mathrm{Ca}^{2+}$ withdrawal on $\ell^{125} I / \alpha-B t x$ binding to retina cultures

The cells were grown in COM and exposed to the various culture conditions listed below from days 7 to 11 . The concentrations of the different agents were as in Tables I, II, and III. The data are from three different experiments and represent the mean $\pm \mathrm{SD}$ of three to four determinations, each. The SD of controls was between 9 and $12 \%$.

\begin{tabular}{lc}
\hline \multicolumn{1}{c}{ Culture Condition } & $\begin{array}{c}{\left[{ }^{125} \mathrm{I}\right] \alpha-\text { Btx Bound/Dish }} \\
(\% \text { control })\end{array}$ \\
\hline + Veratrine & $65 \pm 5^{a}$ \\
+ Tetrodotoxin & $160 \pm 12^{a, b}$ \\
+ 8-bromo-cAMP & $150 \pm 10^{a}$ \\
+ EGTA & $174 \pm 14^{a}$ \\
+ 8-Bromo-cAMP + veratrine & $89 \pm 6$ \\
+ 8-Bromo-cAMP + tetrodotoxin & $182 \pm 4^{a, b}$ \\
+ 8-Bromo-cAMP + EGTA & $201 \pm 4^{a}$ \\
+ Dibutyryl-cGMP & $67 \pm 8^{a}$ \\
+ Dibutyryl-cGMP + veratrine & $60 \pm 9^{a}$ \\
+ Dibutyryl-cGMP + tetrodotoxin & $95 \pm 10$ \\
+ Dibutyryl-cGMP + EGTA & $112 \pm 6$ \\
+ Veratrine + EGTA & $124 \pm 8^{a}$ \\
+ Tetrodotoxin + EGTA & $172 \pm 12^{a}$ \\
+ D600 & $187 \pm 17^{a}$ \\
+ D600 + tetrodotoxin & $181 \pm 8^{a}$ \\
\hline
\end{tabular}

${ }^{a}$ Significantly different from control cultures: $p<0.01$.

${ }^{b}$ Significantly different from each other: $p<0.05$. 
may stimulate receptor accumulation by reducing $\mathrm{Ca}^{2+}$ influx.

Effects of different culture conditions on protein synthesis in retina cultures. The effects on $\alpha$-Btx receptor accumulation of membrane depolarization, cyclic nucleotide derivatives, and EGTA were not caused by overall changes in protein synthesis of the cell cultures. At the concentrations routinely used, veratrine, tetrodotoxin, 8bromo-cAMP, dibutyryl-cGMP, and $\mathrm{MgCl}_{2}$ had no significant effect on the incorporation of $\left[{ }^{3} \mathrm{H}\right]$ leucine into trichloroacetic acid-precipitable material (Table V). EGTA significantly reduced protein synthesis, presumably by detaching some cells (see below). This effect was, however, in contrast to its stimulatory action on $\alpha$-Btx receptor accumulation.

Effects of different culture conditions on cell morphology and neuron numbers in retina cultures. The additions to the culture medium of veratrine $(59 \mu \mathrm{g} / \mathrm{ml})$, tetrodotoxin $(10 \mu \mathrm{M}), 8$-bromo-cAMP $(200 \mu \mathrm{M})$, or dibutyryl-cGMP $(500 \mu \mathrm{M})$ all had no significant effect on the typical morphology (see Betz and Müller, 1982) of the retina cultures (data not shown). Because of the high cell density and extensive cell aggregation in the cultures used in this study, accurate cell counts could not, however, be obtained. EGTA $(2 \mathrm{~mm})$ produced a reduction in neuron size and neuronal cell aggregates. Also, detached cells were seen in the medium under this condition.

By using autoradiographic techniques, it has previously been shown that in 4- to 6-day-old retina cultures $\alpha$-Btx binds to roughly 20 to $30 \%$ of the total and about $40 \%$ of the neuronal cell population (Vogel et al., 1976; Betz, 1981a; Betz and Müller, 1982). Here, the determination of total protein was routinely used to monitor changes in cell number under the various culture conditions. Despite the fact that this assay proved to be very reliable in detecting general cytotoxic effects on neurons, minor alterations in the subpopulation of $\alpha$-Btx-binding cells may not have been detected. Different observations, however, suggest that the effects on $\alpha$-Btx binding described above were not caused by respective changes in

TABLE V

Effect of different culture conditions on protein synthesis in retina cultures

The cells were grown in COM for 3 to 4 days, and then fresh COM, containing $1 \mu \mathrm{Ci} / \mathrm{ml}$ of $\left[{ }^{3} \mathrm{H}\right]$ leucine and the additions specified below, was added. After another 2 days of incubation, the incorporation of $\left[{ }^{3} \mathrm{H}\right]$ leucine in trichloroacetic acid-precipitable material was determined. The data are pooled from three different experiments using five culture dishes, each. The SD of controls was between 5 and $10 \%$. In all experiments, $\leq 2.5 \%$ of the total ${ }^{3} \mathrm{H}$ radioactivity present in the culture medium was incorporated into the cells.

\begin{tabular}{lc}
\hline \multicolumn{1}{c}{ Culture Condition } & $\begin{array}{c}{\left[{ }^{3} \mathrm{H}\right] \text { Leucine Incorporated }} \\
\text { (\% control) }\end{array}$ \\
\hline + Veratrine $(59 \mu \mathrm{g} / \mathrm{ml})$ & $85 \pm 17$ \\
+ Tetrodotoxin $(10 \mu \mathrm{M})$ & $96 \pm 7$ \\
+ 8 -Bromo-cAMP $(200 \mu \mathrm{M})$ & $115 \pm 5$ \\
+ Dibutyryl-cGMP $(500 \mu \mathrm{M})$ & $93 \pm 15$ \\
+ EGTA $(2.0 \mathrm{mM})$ & $76 \pm 6^{a}$ \\
+ $\mathrm{MgCl}_{2}(20 \mathrm{mM})$ & $96 \pm 14$ \\
+ Cycloheximide $(20 \mu \mathrm{g} / \mathrm{ml})$ & $3 \pm 1^{a}$
\end{tabular}

${ }^{a}$ Significantly different from control cultures: $p<0.01$. the number of $\alpha$-Btx-binding cells: (i) At the time when cultures were prepared, retinal neurons are postmitotic (Kahn, 1974). Also, during days 1 to 6 in vitro, there is no major death of retinal neurons (Betz and Müller, 1982). Drugs that produced an increase in $\alpha$-Btx binding, i.e., tctrodotoxin, 8-bromo-cAMP, or D600, are thus unlikely to act by stimulating mitosis or by improving the survival of the toxin-binding neurons. (ii) For many types of neurons, including cholinergic cells from chick retina, depolarization by high $\mathrm{K}^{+}$or veratrum alkaloids has been shown to enhance neuronal survival, whereas tetrodotoxin can reduce it and even cause cell death (Scott, 1977; Chalazonitis and Fischbach, 1980; Betz, 1981b; Nishi and Berg, 1981). These effects are opposite to what is found for $\alpha$-Btx binding. (iii) Retinal neurons can be grown under conditions which minimize non-neuronal cell proliferation, but which do not affect the accumulation of $\alpha$-Btx receptors (Betz and Müller, 1982). Also, under these conditions, the number of $\alpha$-Btx-binding sites is proportional to the number of cells plated (Betz and Müller, 1982). Using such retina cultures at low cell density, $56 \mathrm{mM} \mathrm{K}{ }^{+}, 200 \mu \mathrm{M}$ 8-bromo-cAMP, or $500 \mu \mathrm{M}$ dibutyryl-cGMP all did not produce a significant change in the number of neurons per visual field when present from day 1 to 6 (variation $\pm 20 \%$ of control). Tetrodotoxin at $10 \mu \mathrm{M}$, however, reduced it by about $30 \%$ and also decreased process formation. Autoradiography of these cultures with $\left[{ }^{125} \mathrm{I}\right] \alpha$-Btx performed as described previously (Betz and Müller, 1982) did not reveal major alterations in the proportion of $\alpha$-Btx-binding neurons upon treatment with high $\mathrm{K}^{+}$or dibutyryl-cGMP $(\mathrm{H}$. Betz, unpublished observation). These data, despite being preliminary, suggest that the changes in $\alpha$-Btx binding observed under the different culture conditions are mainly caused by respective changes in the accumulation of receptor sites per cell.

Effects of different culture conditions on the incorporation into the cell surface and on the loss from the cell surface of $\alpha$-Btx receptors. In order to investigate whether the different culture conditions used above affected $\alpha$-Btx receptor accumulation at the level of receptor synthesis and/or insertion into the plasma membrane, or of degradation and/or internalization, respectively, two types of experiments were performed.

$i$. The reappearance on the cell surface of new $\alpha$-Btx receptors was determined after the irreversible blockade of the preexisting receptor sites by a long $\alpha$-toxin isolated from $D$. viridis venom, $\alpha$-mambatoxin (Shipolini et al., 1973; Patrick et al., 1980). This $\alpha$-toxin has been shown to bind to neuronal $\alpha$-Btx-binding sites in a quasi-irreversible fashion (half-time of dissociation $\geq 3$ days; $\mathrm{Pa}$ trick et al., 1980; H. Betz, unpublished results). In chick retina cultures, $\alpha$-mambatoxin protected $>96 \%$ of the $\alpha$ Btx-binding sites with a $K_{\mathrm{D}}<0.5 \mathrm{~nm}$ (data not shown).

Using 6-day-old cultures preincubated with $\alpha$-mambatoxin, veratrine, and $56 \mathrm{mM} \mathrm{K} \mathrm{K}^{+}$reduced the accumulation of new cell surface receptors by $30 \%$ during a $24-\mathrm{hr}$ incubation period (Table VI). Tetrodotoxin, 8-bromocAMP, and EGTA, in contrast, increased receptor accumulation by 30 to $70 \%$. Dibutyryl-cGMP had no significant effect. This is in accord with its delayed action on $\alpha$-Btx receptor accumulation. At concentrations which 
TABLE VI

Reappearance of $\left[{ }^{125} I\right] \alpha-B t x$-binding sites after $\alpha$-Btx receptor blockade by $\alpha$-mambatoxin

Retina cultures were grown in COM for 6 days as described under "Materials and Methods." The cultures were then incubated with 100 $\mathrm{nM} \alpha$-mambatoxin at $37^{\circ} \mathrm{C}$ for $1 \mathrm{hr}$. After three washes with prewarmed DMEM, the cells received fresh COM containing the additions specified below. After another $24 \mathrm{hr}$ of cultivation, the binding of $\left[{ }^{125} \mathrm{I}\right] \alpha$-Btx was determined. The results are expressed as percentage $\pm \mathrm{SD}$ of $\left[{ }^{125} \mathrm{I}\right] \alpha-$ Btx binding to $\alpha$-mambatoxin-treated cultures that had received fresh COM only ( $n=3$ to 4 ). Total $\left[{ }^{125} \mathrm{I}\right] \alpha$-Btx binding in untreated cultures was $70 \mathrm{fmol} / \mathrm{dish}$; the SD of controls was $7 \%$.

\begin{tabular}{lc}
\hline \multicolumn{1}{c}{ Culture Condition } & $\begin{array}{c}\left.{ }^{125} \mathrm{I}\right] \alpha-\text { Btx Bound/Dish } \\
(\% \text { control })\end{array}$ \\
\hline$+56 \mathrm{mM} \mathrm{K}^{+}$ & $75 \pm 4^{a}$ \\
+ Veratrine $(59 \mu \mathrm{g} / \mathrm{ml})$ & $70 \pm 5^{a}$ \\
+ Tetrodotoxin $(10 \mu \mathrm{M})$ & $137 \pm 7^{a}$ \\
+ 8-Bromo-cAMP $(200 \mu \mathrm{M})$ & $133 \pm 6^{a}$ \\
+ Dibutyryl-cGMP $(500 \mu \mathrm{M})$ & $94 \pm 3$ \\
+ EGTA $(2 \mathrm{mM})$ & $168 \pm 9^{a}$ \\
+ Cycloheximide $(20 \mu \mathrm{g} / \mathrm{ml})$ & $32 \pm 3^{a}$ \\
\hline
\end{tabular}

${ }^{a}$ Significantly different from control cultures: $p<0.01$.

inhibited protein synthesis by $>95 \%$, cycloheximide reduced the accumulation of new cell surface receptors to $32 \%$ of that of controls. Presumably, the sites appearing in the presence of cycloheximide corresponded to "latent" preexisting $\alpha$-Btx receptors which were in transit to the cell surface at the time of $\alpha$-mambatoxin labeling (Devreotes et al., 1977; Patrick et al., 1977). In addition, a small portion $(<20 \%)$ of the bound $\alpha$-mambatoxin may dissociate rapidly from its receptor site $(\mathrm{H}$. Betz, unpublished observation).

$i i$. The loss of $\alpha$-Btx receptors from the cell surface was followed after the inhibition of protein synthesis by cycloheximide. The addition to the culture medium of 20 $\mu \mathrm{g} / \mathrm{ml}$ of cycloheximide led to a continuous loss of $\left[{ }^{125} \mathrm{I}\right]$ $\alpha$-Btx-binding sites from the cultures for up to $10 \mathrm{hr}$ (Fig. 2). Usually, the rate of receptor disappearance in the presence of cycloheximide was somewhat faster in younger compared to older cultures $\left(t_{1 / 2}\right.$ about $10 \mathrm{hr}$ in 2-day-old cultures, 16 to $18 \mathrm{hr}$ in 6 to 7 -day-old cultures). These values are in good agreement with previous determinations of $\alpha$-Btx receptor half-life in dissociated chick sympathetic ganglia (Carbonetto and Fambrough, 1979). As shown in Table VII, veratrine, tetrodotoxin, 8-bromocAMP, dibutyryl-cGMP, EG'TA, or $\mathrm{Ca}^{2+}$-free defined medium all had no detectable effect on the loss of cell surface $\alpha$-Btx receptors measured under these conditions. Control experiments showed that the cycloheximide treatment had only a small effect on the rate of degradation of total cellular proteins: in 4-day-old cultures prelabeled with $\left[{ }^{3} \mathrm{H}\right]$ leucine, $20 \mu \mathrm{g} / \mathrm{ml}$ of cycloheximide reduced protein degradation during an 8-hr incubation period to $78 \pm 2 \%$ of that in control cultures ( 8 to $10 \%$ of total cellular protein degraded during $8 \mathrm{hr}$ ).

These results suggest that the rates of $\alpha$-Btx receptor internalization and/or degradation are not significantly changed under these different culture conditions. It should, however, be noted that alterations in the rate of $\alpha$-Btx receptor loss $<25$ to $30 \%$ may not have been detected by the experimental approach used. As all culture conditions produced changes in the rate of receptor

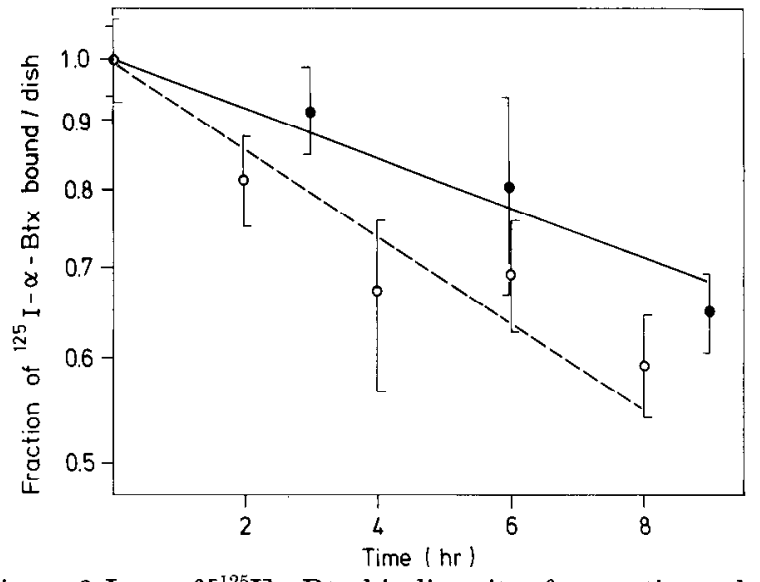

Figure 2. Loss of $\left[{ }^{125} \mathrm{I}\right] \alpha$-Btx-binding sites from retina cultures after the inhibition of protein synthesis by cycloheximide. The cells were grown in COM as detailed under "Materials and Methods." At the onset of the experiments, eight dishes were removed for the determination of $\left[{ }^{125} \mathrm{I}\right] \alpha$-Btx binding. The remaining dishes received fresh COM containing $20 \mu \mathrm{g} / \mathrm{ml}$ of cycloheximide. $\left[{ }^{125} \mathrm{I}\right] \alpha$-Btx binding was then determined at the times indicated. The data are expressed as fractions of $\left[{ }^{125} \mathrm{I}\right] \alpha-$ Btx binding at the time of cycloheximide addition (12 fmol/dish for 2-day-old cultures; $47 \mathrm{fmol} /$ dish for 6 -day-old cultures) and represent the mean $\pm S D$ of three to four determinations. $O, 2$ day-old cultures; 6 -day-old cultures.

\section{TABLE VII}

Effects of veratrine, cyclic nucleotide derivatives, and $\mathrm{Ca}^{2+}$ withdrawal on the loss of $\left[{ }^{125} I\right] \alpha-B t x$-binding sites from retina cultures after inhibition of protein synthesis by cycloheximide

Retina cultures were grown in COM for 2 to 5 days. Eight to 10 control dishes then were used for the determination of $\left[{ }^{125} \mathrm{I}\right] \alpha-\mathrm{Btx}$ binding. Parallel cultures received the media listed below containing 20 $\mu \mathrm{g} / \mathrm{ml}$ of cycloheximide. This concentration of the drug inhibited $\left[{ }^{3} \mathrm{H}\right]$ leucine incorporation into protein in all media by $>95 \%$ (Table IV; also data not shown). After another $8 \mathrm{hr}$ of cultivation, $L^{125} \mathrm{I} J \alpha-\mathrm{Btx}$ binding to the cultures was again determined ( $n=3$ to 4$)$. The half-time $\left(t_{1 / 2}\right)$ of $\alpha$-Btx receptor loss was calculated assuming first-order decay kinetics. The experimental variation of the determined half-times was 2 to $4 \mathrm{hr}$. The binding of $\left[{ }^{125} \mathrm{I}\right] \alpha$-Btx to control cultures was: experiment $\mathrm{A}$ (2-day-old cultures), $11 \mathrm{fmol} /$ dish; experiment B (4-day-old cultures), $42 \mathrm{fmol} / \mathrm{dish}$.

\begin{tabular}{lc}
\hline \multicolumn{1}{c}{ Culture Condition } & $t_{1 / 2}(\mathrm{hr})$ \\
\hline Experiment A & \\
COM & 10 \\
COM + EGTA $(2 \mathrm{mM})$ & 14 \\
$\mathrm{Ca}^{2+}$-free N1 & 13 \\
Experiment B & \\
COM & 12 \\
COM + veratrine $(59 \mu \mathrm{g} / \mathrm{ml})$ & 12 \\
COM + tetrodotoxin $(10 \mu \mathrm{M})$ & 13 \\
COM + 8-bromo-cAMP $(200 \mu \mathrm{M})$ & 15 \\
COM + dibutyryl-cGMP $(500 \mu \mathrm{M})$ & 14 \\
\hline
\end{tabular}

appearance on the cell surface which can account for the observed differences in $\alpha$-Btx binding, it seems justified to conclude that membrane depolarization, 8-bromocAMP, and $\mathrm{Ca}^{2+}$ withdrawal alter the accumulation of the $\alpha$-Btx receptor in retina cultures by primarily modulating its rate of synthesis and/or incorporation into the neuronal plasma membrane. 


\section{Discussion}

The present paper shows that the depolarization of chick retina cultures by veratrum alkaloids or high $\mathrm{K}^{+}$ reduces the accumulation of cell surface $\alpha$-Btx-binding sites without significantly affecting general protein synthesis. Also, in morphologically differentiated (Vogel and Nirenberg, 1976; Betz and Müller, 1982) retinal cultures, tetrodotoxin, a blocker of sodium-dependent action potentials, specifically increased $\alpha$-Btx receptor accumulation. 'These observations cannot be explained by respective changes in the number of $\alpha$-Btx-binding neurons (see "Results"). They are therefore consistent with the interpretation that the number of cell surface $\alpha$-Btx receptors on chick retinal neurons is regulated by their transmembrane potential; i.e., in vivo, their electrical activity. This mode of regulation has been amply documented for the nicotinic acetylcholine receptor of vertebrate skeletal muscle (for review see Fambrough, 1979).

The regulation of $\alpha$-Btx receptor accumulation in our retina culture system exhibited additional features which were comparable to those of the nicotinic acetylcholine receptor of muscle cells in vitro: $(i)$ the addition of cAMP derivatives to the culture medium increased the number of $\alpha$-Btx receptor sites of the cultures (cf. Betz and Changeux, 1979; Blosser and Appel, 1980); (ii) the addition of dibutyryl-cGMP reduced $\alpha$-Btx receptor accumulation (cf. Betz and Changeux, 1979); (iii) the blocker of voltage-dependent $\mathrm{Ca}^{2+}$ channels, D600, increased the number of $\alpha$-Btx receptors (cf. Prives, 1976; Birnbaum et al., 1980). These observations support the hypothesis that the $\alpha$-Btx receptor of chick retina shares not only biochemical, pharmacological, and immunological properties with the peripheral nicotinic acetylcholine receptor of skeletal muscle and fish electric organ (Vogel and Nirenberg, 1976; Wang et al., 1978; Betz, 1981a), but also underlies the same mechanism of regulation, and thus may indeed be a cholinergic receptor protein.

The data on $\alpha$-Btx receptor regulation in chick retina cultures presented in this investigation are consistent with a previously postulated model for the regulation of muscle acetylcholine receptor (Betz and Changeux, 1979; Betz and Rehm, 1980a): (i) an enhanced accumulation of $\alpha$-Btx receptors results from an activation of the adenylate cyclase system and an increase in intracellular cAMP; (ii) $\alpha$-Btx receptor accumulation is negatively controlled by membrane depolarization. Several lines of evidence suggest that this latter regulatory pathway is coupled to the activation of voltage-sensitive $\mathrm{Ca}^{2+}$ channels and an increase in intracellular $\mathrm{Ca}^{2+}$ concentration: (1) Membrane depolarization by increasing the $\mathrm{K}^{+}$concentration of the culture media became effective only below a certain transmembrane potential (approximately -30 to $-20 \mathrm{mV}$ ). This is consistent with the activation of voltage-dependent channels exhibiting a distinct threshold potential (Kostyuk, 1981). (2) In differentiated retina cultures, the blocker of voltage-dependent $\mathrm{Ca}^{2+}$ channels, D600, stimulated $\alpha$-Btx receptor accumulation to an extent similar to that of the blocker of voltage-dependent sodium channels, tetrodotoxin. It should, however, be noted here that the specificity of D600 for voltage-dependent $\mathrm{Ca}^{2+}$, but not $\mathrm{Na}^{+}$channels, has recently been questioned (Frelin et al., 1982). (3) Reducing the free $\mathrm{Ca}^{2+}$ concentration of the medium by the addition of EGTA or using a $\mathrm{Ca}^{2+}$-free defined medium increased $\alpha$-Btx receptor levels of the retina cultures.

In the muscle system, experimental manipulations leading to alterations in intracellular $\mathrm{Ca}^{2+}$ levels have been shown to affect acetylcholine receptor synthesis in a manner consistent with this hypothesis (Birnbaum et al., 1980; Pezzementi and Schmidt, 1981; but see McManaman et al., 1981). However, in both the muscle and the retina system, the chain of events following depolarization-induced $\mathrm{Ca}^{2+}$ influx is not yet clear. From the effect of externally applied dibutyryl-cGMP, and considering the well documented increase in cGMP upon depolarization of different types of electrically excitable cells (Beam et al., 1978; Nestler et al., 1978; Study et al., 1978), we had proposed that both $\mathrm{Ca}^{2+}$ and cGMP may constitute the second messengers in the activity-dependent control of muscle acetylcholine receptor synthesis (Betz and Changeux, 1979; Betz and Rehm, 1980a). The data presented here for the retinal $\alpha$-Btx-binding protein are not in support of this model: $(i)$ the cGMP analogue 8-bromo-cGMP did not reduce $\alpha$-Btx receptor accumulation; (ii) the effect of dibutyryl-cGMP added to the culture medium was slow (more than 1 day of culture). This contrasts with the more rapid effects of membrane depolarization by veratrine or high $\mathrm{K}^{+}$(less than $24 \mathrm{hr}$ ). It should, however, be noted that, so far, nothing is known about the stability of cyclic nucleotide derivatives under our culture conditions or about their rate of penetration into the cells and their eventual inhibitory effects on cyclic nucleotide phosphodiesterases; i.e., secondary influences on the cAMP system (Weiss and Hait, 1977). For muscle, the possible involvement of cGMP in the regulation of acetylcholine receptor synthesis has been questioned: $(i)$ different attempts to demonstrate a correlation between the number of acetylcholine receptor sites and cGMP levels under various conditions of membrane depolarization and/or blockade of spontaneous activities have failed (Betz, 1980; McManaman et al., 1982); (ii) increasing intracellular cGMP in muscle cultures by sodium nitroprusside reduced acetylcholine receptor levels only at very high drug concentrations (McManaman et al., 1982). In the latter experiments, however, isobutyl methylxanthine, a phosphodiesterase inhibitor, was usually included. This may affect intracellular cAMP levels and thus produce antagonistic effects on muscle acetylcholine receptor synthesis. Also, the possibility has to be considered that the addition of dibutyryl-cGMP to the medium may change the $\mathrm{Ca}^{2+}$ permeability of the cells (Ferrendelli, 1978). In any case, a conclusive evaluation of the role of cGMP in the activity-dependent regulation of postsynaptic proteins will require analysis in more simplified in vitro systems.

In skeletal muscle, the changes in nicotinic acetylcholine receptor levels produced by membrane depolarization, cyclic nucleotide derivatives, or $\mathrm{Ca}^{2+}$ antagonists all have been shown to involve alterations in the rate of receptor synthesis, but not receptor degradation (Prives, 1976; Betz and Changeux, 1979; Birnbaum et al., 1980; Blosser and Appel, 1980; McManaman et al., 1981, 1982; Pezzementi and Schmidt, 1981). The same appears to be 
valid for the regulation of the neuronal $\alpha$-Btx-binding protein investigated here. Although neuronal $\alpha$-Btx receptor synthesis and/or degradation cannot yet be monitored directly, the experiments on $\alpha$-Btx receptor reappearance after blocking preexisting receptor sites with $\alpha$-mambatoxin, as well as on the loss of $\alpha$-Btx-binding sites after inhibiting protein synthesis by cycloheximide, support the conclusion that it is indeed the rate of synthesis, and not of degradation, of the $\alpha$-Btx receptor which is altered by the different culture conditions described in this paper. Together with the pharmacological similarity of $\alpha$-Btx receptor accumulation to that of muscle acetylcholine receptor, these findings support the promising view that the synthesis of postsynaptic membrane proteins in the peripheral and central nervous system may underlie general mechanisms of trans-synaptic regulation.

\section{References}

Beam, K. G., E. J. Nestler, and P. Greengard (1977) Increased cyclic GMP levels associated with contraction in muscle fibers of the giant barnacle. Nature 267: 534-536.

Betz, H. (1980) Effects of drug-induced paralysis and depolarization on acetylcholine receptor and cyclic nucleotide levels of chick muscle cultures. FEBS Lett. 118: 289-292.

Betz, H. (1981a) Characterization of the $\alpha$-bungarotoxin receptor in chick-embryo retina. Eur. J. Biochem. 117: 131-139.

Betz, H. (1981b) Choline acetyltransferase activity in chick retina cultures: Effect of membrane depolarizing agents. Brain Res. 223: 190-194.

Betz, H., and J. P. Changeux (1979) Regulation of muscle acetylcholine receptor synthesis in vitro by cyclic nucleotide derivatives. Nature 278: 749-752.

Betz, H., and U. Müller (1982) Culture of chick embryo neural retina in serum-free medium. Exp. Cell Res. 138: 297-302.

Betz, H., and H. Rehm (1980a) Assembly and turnover of the subsynaptic membrane. In Biological Chemistry of Organelle Formation, T. Bücher, W. Sebald, and H. Weiss, eds., pp. 175-186, Springer-Verlag; Heidelberg.

Betz, H., and H. Rehm (1980b) Receptors for $\alpha$ - and $\beta$-bungarotoxin in chick embryo retina. Soc. Neurosci. Abstr. 6: 253.

Betz, H., and U. Weiser (1976) Protein degradation and proteinases during yeast sporulation. Eur. J. Biochem. 62: 6576.

Betz, H., J. P. Bourgeois, and J. P. Changeux (1980) Evolution of cholinergic proteins in developing slow and fast skeletal muscles in chick embryo. J. Physiol. (Lond.) 302: 197-218.

Betz, H., D. Graham, and H. Rehm (1982) Identification of polypeptides associated with a putative neuronal nicotinic acetylcholine receptor. J. Biol. Chem. 257: 11390-11394.

Birnbaum, M., M. A. Reiss, and A. Shainberg (1980) Role of calcium in regulation of $\mathrm{ACh}$ receptor synthesis in cultured muscle cells. Pflugers Arch. 385: 37-43.

Blosser, J. C., and S. H. Appel (1980) Regulation of acetylcholine receptor by cyclic AMP. J. Biol. Chem. 253: 3088-3093.

Boström, S. L., B. Ljung, S. Mardh, S. Forssen, and E. Thulin (1981) Interaction of the antihypertensive drug felodipine with calmodulin. Nature 292: 777-778.

Bottenstein, J. E., S. D. Skaper, S. S. Varon, and G. H. Sato (1980) Selective survival of neurons from chick embryo sensory ganglionic dissociates utilizing serum-free supplemented medium. Exp. Cell Res. 125: 183-190.

Bourgeois, J. P., H. Betz, and J. P. Changeux (1978) Efféts de la paralysie chronique de l'embryon de poulet par le flaxédil sur le développement de la jonction neuro-musculaire. C. $R$. Acad. Sci. Paris 286: 773-776.

Burden, S. (1977) Development of the neuromuscular junction in the chick embryo: The number, distribution, and stability of acetylcholine receptors. Dev. Biol. 57: 317-329.

Carbonetto, S., and D. M. Fambrough (1979) Synthesis, insertion into the plasma membrane, and turnover of $\alpha$-bungarotoxin receptors in chick sympathetic neurons. J. Cell Biol. 81 : $555-569$.

Chalazonitis, A., and G. D. Fischbach (1980) Elevated potassium induced morphological differentiation of dorsal root ganglion neurons in dissociated cell culture. Dev. Biol. 78: 173-183.

Daniels, M. P., and Z. Vogel (1981) Localization of $\alpha$-bungaroloxin binding sites in synapses of the developing chick retina. Brain Res. 201: 45-56.

Devreotes, P. N., J. M. Gardner, and D. M. Fambrough (1977) Kinetics of biosynthesis of acetylcholine receptor and subsequent incorporation into plasma membrane of cultured chick skeletal muscle. Cell 10: 365-373.

Drachman, D. B., and F. Witzke (1972) Trophic regulation of acetylcholine sensitivity of muscle. Effect of electrical stimulation. Science 176: 514-516.

Fambrough, D. M. (1979) Control of acetylcholine receptors in skeletal muscle. Physiol. Rev. 59: 165-227.

Ferrendelli, J. A. (1978) Distribution and regulation of cyclic GMP in the central nervous system. Adv. Cyclic Nucleotide Res. 9: 453-464.

Frelin, C., P. Vigne, and M. Lazdunski (1982) Biochemical evidence for pharmacological similarities between $\alpha$-adrenoreceptors and voltage-dependent $\mathrm{Na}^{+}$and $\mathrm{Ca}^{2+}$ channels. Biochem. Biophys. Res. Commun. 106: 967-973.

Giacobini, G., G. Filogamo, M. Weber, P. Boquet, and J. P. Changeux (1973) Effects of a snake venom $\alpha$-neurotoxin on the development of innervated skeletal muscles in chick embryo. Proc. Natl. Acad. Sci. U. S. A. 70: 1708-1712.

Hall, Z. W., and C. G. Reiness (1977) Electrical stimulation of denervated muscles reduces incorporation of methionine into the ACh receptor. Nature 268: 655-657.

Kahn, A. J. (1974) An autoradiographic analysis of the time of appearance of neurons in the developing chick retina. Dev. Biol. 38: 30-40.

Kostyuk, P. G. (1981) Calcium ionic channels in electrically excitable membranes. Neuroscience 5: 945-959.

Lichtstein, P., H. R. Kaback, and A. J. Blume (1979) Use of a lipophilic cation for determination of membrane potential in neuroblastoma-glioma hybrid cell suspensions. Proc. Natl. Acad. Sci. U. S. A. 76: 650-654

Lømo, T., and J. Rosenthal (1972) Control of ACh sensitivity by muscle activity in the rat. J. Physiol. (Lond.) 221: 493513.

Lømo, T., and C. R. Slater (1980) Control of junctional acetylcholinesterase by neural and muscular influence in the rat. J. Physiol. (Lond.) 303: 191-202.

Lowry, O. H., N. J. Rosebrough, A. L. Farr, and R. J. Randall (1951) Protein measurement with the Folin phenol reagent J. Biol. Chem. 193: 265-275.

McManaman, J. L., J. C. Blosser, and S. H. Appel (1981) The effect of calcium on acetylcholine receptor synthesis. J. Neurosci. 1: 771-776.

McManaman, J. L., J. C. Blosser, and S. H. Appel (1982) Inhibitors of membrane depolarization regulate acetylcholine receptor synthesis by a calcium-dependent, cyclic nucleotideindependent mechanism. Biochim. Biophys. Acta 720: 28-35.

Morley, B. J., and G. E. Kemp (1981) Characterization of a putative nicotinic acetylcholine receptor in mammalian brain. Brain Res. Rev. 3: 81-104.

Nestler, E. J., K. G. Beam, and P. Greengard (1978) Nicotinic cholinergic stimulation increases cyclic GMP levels in vertebrate muscle. Nature 27: 451-453.

Nishi, R., and D. K. Berg (1981) Effects of high $\mathrm{K}^{+}$concentra- 
tion on the growth and development of ciliary ganglion neurons in cell culture. Dev. Biol. 87: 301-307.

Norman, R. I., F. Mehraban, E. A. Barnard, and J. O. Dolly (1982) Nicotinic acetylcholine receptor from chick optic lobe. Proc. Natl. Acad. Sci. U. S. A. 79: 1321-1325.

Oswald, R. E., and J. A. Freeman (1981) Alpha-bungarotoxin binding and central nervous system nicotinic acetylcholine receptors. Neuroscience $6: 1-14$.

Patrick, J., J. McMillan, H. Wolfson, and J. C. O'Brien (1977) Acetylcholine receptor metabolism in a non-fusing muscle cell line. J. Biol. Chem. 252: 2143-2153.

Patrick, J., W. B. Stallcup, M. Zaranelli, and P. Ravdin (1980) Binding properties of a neurotoxin from the venom of the green mamba, Dendroaspis viridis. J. Biol. Chem. 255: 526533.

Pezzementi, L., and J. Schmidt (1981) Ryanodine alters the rate of acetylcholine receptor synthesis in chick skeletal muscle cultures. J. Biol. Chem. 256: 12651-12654.

Prives, J. M. (1976) Appearance of specialized cell membrane components during differentiation of embryonic skeletal muscle cells in culture. In Surface Membrane Receptors, R. A. Bradshaw, W. A. Frazier, R. C. Merrell, D. I. Gottlieb, and R. A. Hogue-Angeletti, eds., pp. 363-375, Plenum Publishing Corp., New York.

Rubin, L. L., S. M. Schuetze, C. L. Weill, and G. D. Fischbach (1980) Regulation of acetylcholinesterase appearance at neuromuscular junctions in vilru. Nature 283: 264-267.
Scott, B. S. (1977) The effects of elevated potassium on the time course of neuron survival in cultures of dissociated dorsal root ganglia. J. Cell. Physiol. 91: 305-316.

Shipolini, R. A., G. S. Bailey, J. A. Edwardson, and B. E. C. Banks (1973) Separation and characterization of polypeptides from the venom of Dendroaspis viridis. Eur. J. Biochem. 40: $337-344$.

Study, R. E., X. O. Breakefield, T. Bartfai, and P. Greengard (1978) Voltage-sensitive calcium channels regulate guanosine $3^{\prime}, 5^{\prime}$-cyclic monophosphate levels in neuroblastoma cells. Proc. Natl. Acad. Sci. U. S. A. 75: 6295-6299.

Vogel, Z., and M. Nirenberg (1976) Localization of acetylcholine receptors during synaptogenesis in retina. Proc. Natl. Acad. Sci. U. S. A. 73: 1806-1810.

Vogel, Z., M. P. Daniels, and M. Nirenberg (1976) Synapse and acetylcholine receptor synthesis by neurons dissociated from retina. Proc. Natl. Acad. Sci. U. S. A. 73: 2370-2374.

Vogel, Z., G. J. Maloney, A. Ling, and M. P. Daniels (1977) Identification of synaptic acetylcholine receptor sites in retina with peroxidase-labeled $\alpha$-bungarotoxin. Proc. Natl. Acad. Sci. U. S. A. 74: 3268-3272.

Wang, G. K. S., S. Molinaro, and J. Schmidt (1978) Ligand responses of $\alpha$-bungarotoxin binding sites from skeletal muscle and optic lobe of the chick. J. Biol. Chem. 253: 8507-8512.

Weiss, B., and W. N. Hait (1977) Selective cyclic nucleotide phosphodiesterase inhibitors as potential therapeutic agents. Annu. Rev. Pharmacol. Toxicol. 17: 441-477. 